\title{
Remote sensing enables high discrimination between organic and non-organic cotton for organic cotton certification in West Africa
}

\author{
Antoine Denis ${ }^{1} \cdot$ Bernard Tychon $^{1}$
}

Accepted: 4 May 2015 / Published online: 16 June 2015

(C) INRA and Springer-Verlag France 2015

\begin{abstract}
One of the challenges of organic crop certification is the efficient targeting of the relatively small percentage of risk-sensitive fields that have to be controlled during the regulatory annual in situ inspection. A previous study carried out on wheat and maize in Germany has shown that organic and non-organic crops can be efficiently distinguished by remote sensing. That study pointed to the possibility that these techniques could be used for helping organic crop certification bodies to better target risk-sensitive fields. This study is a first adaptation of that research on organic cotton in southwestern Burkina Faso, West Africa. This study assumed that organic and non-organic cotton, primarily because of their different approaches to fertilization and pest control, would result in bio-chemico-physical differences measurable by both in situ and remote sensing indicators. This study included 100 cotton fields, of which 50 were organic, 28 conventional, and 22 genetically modified. In situ indicators were derived from chlorophyll content, canopy cover, height, and spatial heterogeneity measurements. Remote sensing spectral and spatial heterogeneity indicators were derived from two SPOT 5 satellite images. Discriminant models were then computed. The results show statistically highly significant differences between organic and non-organic cotton fields for both in situ and satellite indicators, using univariate and multivariate linear models, with up to $86 \%$ discrimination performance. This
\end{abstract}

Antoine Denis

Antoine.Denis@ulg.ac.be

1 Water, Environment and Development Unit, Department of Environmental Sciences and Management, Arlon Campus Environment, University of Liège, 185 Avenue de Longwy, 6700 Arlon, Belgium is the first time that the efficiency of using remote sensing to discriminate between organic and non-organic crops is evaluated in a developing country, particularly for cotton, with good discrimination being achieved. Pending further validation, it therefore seems that remote sensing could be used to enhance organic cotton certification in West Africa by enabling more efficient targeting of suspect fields and consequently could contribute to a better development of this sector.

Keywords Organic cotton certification - Organic cotton · Conventional cotton · Genetically modified cotton $\cdot$ Satellite remote sensing · West Africa · Burkina Faso · Comparison

\section{Introduction}

In Burkina Faso, organic cotton has been grown since 2004 and covers about $1 \%$ of the national cotton area (CDE, Centre for Development and Environment of the University of Berne, Helvetas Burkina Faso 2008), with the rest of the area more or less equally shared between conventional and genetically modified cotton (GRAIN 2004). In order to be sold on the international market, organic cotton has to comply with established international standards and rules and to be certified by organic certification bodies. Part of this certification process is a field inspection focused on risk-sensitive areas identified on the basis of several criteria. Provided that biochemico-physical differences (hereafter referred to as "differences") are identified between organic and non-organic cotton fields and that these differences are observable by satellite imagery, the latter could be used, in the beginning of the field certification process, to target for priority control cotton fields declared as organic but shown as suspect by remote sensing indicators (Fig. 1). The use of remote sensing would have the advantages of being a supplementary and independent means 
Fig. 1 Schematic illustration of the study objectives: "Is it possible to discriminate between organic and non-organic cotton fields from satellite images?" Upper left: 15 November 2011 SPOT 5 satellite image of a study area subset with in situ fields shown and leaf chlorophyll content measurement

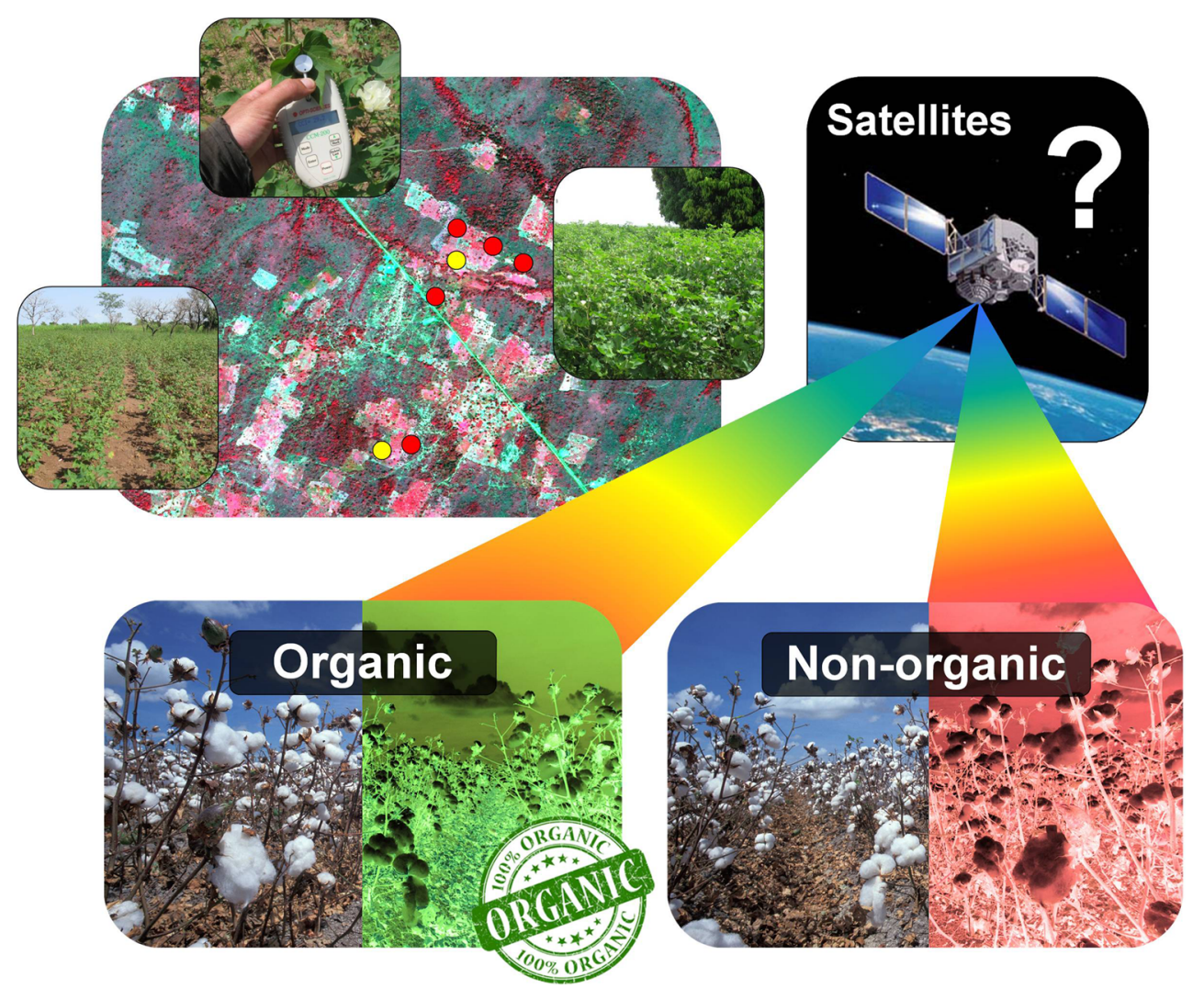

of control, providing a practical approach for remote areas that are sometimes difficult to reach in developing countries' countryside and helping certification bodies to face up to growing organic crop areas to certify.

The operational method could comprise four steps: (i) collecting field geolocalization (usually available) and satellite image(s) of the area targeted for control, (ii) developing a discriminating model from a comparison of indicators derived from satellite image (s) for reference organic and non-organic fields, (iii) using this model to assess the level of confidence for other organic fields, and (iv) in situ inspection for most suspect organic fields.

The objectives of this study were to assess, in the context of southwestern Burkina Faso, (i) the potential differences between organic and non-organic cotton using a range of in situ measurements and (ii) the possibility of helping the organic cotton certification process through the use of remote sensing images, particularly the ability of these images to discriminate between organic and non-organic cotton fields.

\section{Materials and methods}

\subsection{Study area}

The study area was east of Banfora city in southwestern Burkina Faso, West Africa (Fig. 2). The local climate is equatorial with dry winters and savannah (Aw Koeppen climate class) and a low annual temperature amplitude with an annual average of $28^{\circ} \mathrm{C}$. The rainy season coincides with the growing season and lasts from about 15 May to 15 October, the rest of the year being dry. The aridity index, i.e., the ratio of annual precipitation to annual potential evapotranspiration (Le Houérou et al. 1981), is "dry subhumid" with a precipitation deficit of $1025 \mathrm{~mm} /$ year (FAO, German Weather Service DWD and Grieser 2006). The area is flat to slightly hilly, with a mean altitude of $300 \mathrm{~m}$. The study area was selected to include a mix of organic and non-organic cotton fields in an area of $45 \mathrm{~km} \times 35 \mathrm{~km}$.

\subsection{Cotton crop, phenology, and timing in the area}

A range of local cotton varieties is grown in Burkina Faso, but none is particularly earmarked for organic or conventional cultivation. Genetically modified cotton is represented by several varieties of Bt cotton (Noisette 2006). Cotton is generally cultivated in a low-intensive way, farming operations are conducted manually or with work animals, and the crop is always harvested manually (CIRAD and le Développement 2006). The cotton crop is rainfed (CIRAD and le Développement 2006), and the seeding date in the study area occurs between 20 May and 15 July, depending on the onset of the rainy season (Jean-Luc Hofs, CIRAD Biotechnologist, 2011, personal communication). The length of time between seeding and harvest in the study area is about 150 days, depending 
Fig. 2 Location of the study area in southwestern of Burkina Faso and cotton field distribution according to the three management systems: organic, conventional, and genetically modified

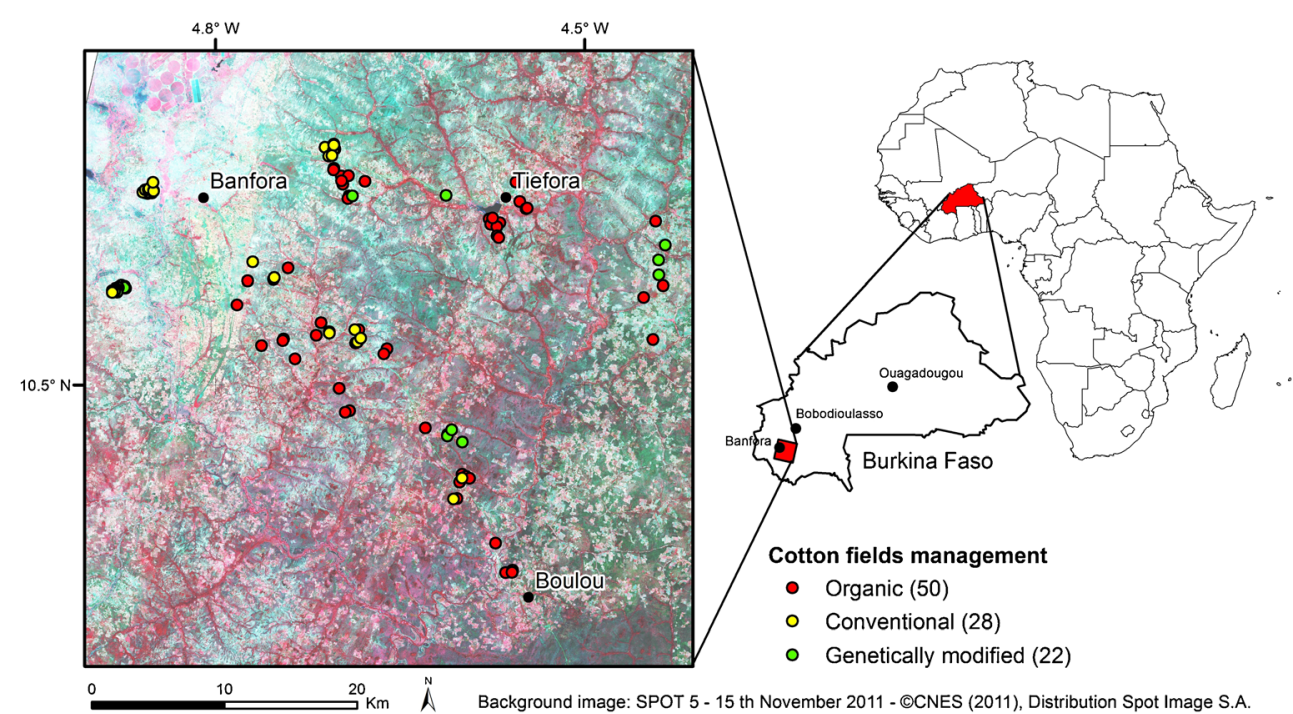

partly on the cotton variety (Abel Gouba, Helvetas Burkina Faso, 2011, personal communication). Cotton blooms while growing, and at a given time, a cotton plant simultaneously carries flower buds, flowers, and bolls. Once the ripe bolls open, cotton fibers appear as white balls. Finally, the leaves wither and the plant dries. The crop is harvested in October and November (Abel Gouba, 2011, personal communication). In any given region at a given time, plant growth stages can vary considerably from one field to another, depending on several factors. These include local climatic conditions (e.g., very late rainfall in some places), institutional reasons (e.g., workers' strike and field wreckage), and management issues (e.g., late input application and poor seed quality, which can require four reseedings, resulting in delays of up to 20 days).

\subsection{Cotton management system definition and differences}

\subsubsection{Cotton management systems definition}

Organic cotton is cultivated according to the international rules of organic agriculture and is subjected to the organic certification process. In particular, synthetic chemical pesticides and fertilizers (Helvetas Burkina Faso 2004), mineral nitrogen fertilizer, and genetically modified organisms (European Commission 2007) are prohibited. The genetically modified cotton grown in Burkina Faso is represented by several varieties of the Bt cotton (Noisette 2006). Conventional cotton is the cotton that has not been genetically modified or certified as organic. Conventional and genetically modified cotton use synthetic chemical pesticides and fertilizers and mineral nitrogen fertilizers.

\subsubsection{Observed differences between organic and non-organic cotton}

A recent study in Burkina Faso of about 100 cotton growers (CDE et al. 2009) shows a clear difference in yield between organic and conventional cotton, with an average of $1100 \mathrm{~kg} /$ ha for conventional cotton and $675 \mathrm{~kg} / \mathrm{ha}$ for organic cotton, i.e., an average of $39 \%$ lower yields. Standard deviations are important, however, with $314 \mathrm{~kg} / \mathrm{ha}$ for organic fields and $391 \mathrm{~kg} / \mathrm{ha}$ for conventional fields, showing considerable yield variability. This study also notes that elite organic farmers can potentially push yields above $1000 \mathrm{~kg} / \mathrm{ha}$. (CDE et al. 2009). According to an expert in Burkina Faso cotton (Georg Felber, Coordinator of the organic and Fairtrade cotton program run by Helvetas Swiss Intercooperation-Burkina Faso from 2007 to 2011, 2011, personal communication), organic cotton fields can usually be differentiated from conventional or genetically modified ones by the naked eye, with less biomass and lower yield being characteristic of organic fields. This expert also notes, however, that a well-managed organic field can look like a conventional or genetically modified one.

The observed yield differences are explained by several factors, including (CDE et al. 2009): (i) conventional management uses chemical synthetic NPK and urea fertilizers and pesticides; (ii) in organic management, natural fertilization is slower and often not enough fertilizer is applied; (iii) the organic cotton development program is fairly new (2004) and involves less developed farms, as well as farmers with less expertise and/or training (Some 2008) in organic cropping techniques, less equipment, less important livestock, and, therefore, a lower quantity of fertilizers and often precarious financial situations; (iv) cultivation in less fertile zones; (v) frequent seed delivery delays from suppliers; and (vi) an increase in new organic management technical staff who lack 
the experience and training to enable them to give farmers adequate advice on applying organic techniques.

Helvetas et al. (2008), however, noted that 2-3 years after conversion to organic methods, most of the organic cotton grown under their project produced yields approximately as good as those obtained through conventional management. This was partly because organic management improves soil fertility (Georg Felber, 2011, personal communication).

No reference of study comparing organic and non-organic cotton with remote sensing was found. Nevertheless, Denis et al. (2012) were able to completely discriminate between organic and non-organic maize and winter wheat in Germany and France using as basic remote sensing indicator as Green NDVI for example.

\subsubsection{Hypothesis on cotton differences from different management systems}

In this study, it was assumed that the differences between organic and non-organic cotton management systems, particularly with regard to the different ways of fertilization and pest control, would produce differences that are measurable using indicators derived from field instruments or satellite imagery, as summarized in Table 1. For organic fields, these differences include less canopy cover, lower chlorophyll content in the plants and smaller plants. It was also assumed that organic cotton fields would present higher spatial heterogeneity given that organic crops cannot benefit from mineral fertilizers, which make nutrients, especially nitrogen, readily available and easy to spread evenly on the field, thus evening out the field's "natural fertility." By contrast, organic fertilizers are usually deposited on a field in piles and then roughly spread, creating characteristic pockets of fertility where the piles were deposited and nearby but showing poorer plant development further away from the piles, resulting in strongly varying cotton development on the organic fields. In addition, it was assumed that the spatial heterogeneity of organic fields is exacerbated by the fact that (i) herbicides are not used in organic management, allowing weeds to develop, often in localized parts of the fields, and (ii) pest control under organic management system tends to be less efficient, enabling diseases to take hold more easily.

\subsection{Data acquisition and indicators computation}

Measurements were taken in organic and non-organic cotton fields in situ during a field survey and with satellite imagery.

\subsubsection{Field survey and sampling}

The field survey was conducted during the first 10 days of October 2011. This period was selected in order to ensure that the cotton plants had reached a growth stage suitable for the study, i.e., after start of main stem elongation and before senescence. The study covered 100 cotton fields, of which 50 were organic and 50 non-organic, the latter being split into 28 conventional and 22 genetically modified (Fig. 2). The fields were selected according to the following criteria: (i) management system (organic, conventional, genetically modified); (ii) spatial distribution, to be representative of the whole study area; (iii) accessibility; (iv) field size, to be big enough to be studied on a satellite image with a spatial resolution of $2.5 \mathrm{~m}$; and (v) availability of the farmer at the time of the measurements. The field boundaries were recorded by GPS. Genetically modified cotton fields accounted for a significantly larger area (mean area $1.29 \mathrm{ha}$ ) than conventional (mean area $0.81 \mathrm{ha}$ ) or organic (mean area $0.88 \mathrm{ha}$ ) ones. The field area varied greatly, both among all the fields and within the different management types (standard deviation of 1.10, 0.62, and 0.66 ha, respectively). In each field, ten plots were selected for study. These plots were more than $10 \mathrm{~m}$ from the field boundary, were at least $5 \mathrm{~m}$ from each other, and, together, were representative of the whole field. For each plot,

Table 1 Differences between organic and non-organic cotton management systems, resulting cotton plant differences, related indicators, and measurement method for in situ measurement and satellite sensing

\begin{tabular}{|c|c|c|c|}
\hline $\begin{array}{l}\text { Differences in cotton management systems } \\
\text { Differences in organic compared with }\end{array}$ & $\begin{array}{l}\text { Differences in cotton plants } \\
\text { non-organic systems }\end{array}$ & Indicators & Measurement method \\
\hline Less fertilizer & Less canopy cover & Field canopy cover & $\begin{array}{l}\text { In situ hemispherical pictures } \\
\text { Satellite "spectral indicators" }\end{array}$ \\
\hline \multirow{2}{*}{$\begin{array}{l}\text { No use of synthetic chemical fertilizer } \\
\text { or mineral nitrogen fertilizer }\end{array}$} & Lower chlorophyll content & Leaf chlorophyll content & In situ chlorophyll content meter \\
\hline & Lower height & Plant height & In situ measuring tape \\
\hline $\begin{array}{l}\text { Less spatial homogeneous fertilizer } \\
\text { application }\end{array}$ & Higher spatial heterogeneity & Field spatial heterogeneity & $\begin{array}{l}\text { Standard deviation by field for other in } \\
\text { situ indicators }\end{array}$ \\
\hline $\begin{array}{l}\text { Less-efficient pest control } \\
\text { No use of synthetic chemical pesticide }\end{array}$ & & & Satellite "spatial heterogeneity indicators" \\
\hline
\end{tabular}


chlorophyll content, height, and canopy cover measurements were taken and the growth stage was recorded.

\subsubsection{In situ indicators}

Height Cotton plant height was measured with a 2-m-long folding rule. The rule was placed at the plant base, and the height was read at the top of plant.

Chlorophyll content Chlorophyll content was estimated using a Chlorophyll Content Meter (CCM-200 from OptiSciences) on one of the upper leaves of the selected plant. The CCM-200 is a hand-held instrument designed for the rapid, non-destructive determination of chlorophyll content of intact leaf samples. Two wavelengths are used to determine absorbance, one falling within the chlorophyll absorbance range (red at $653 \mathrm{~nm}$ ) and the other serving to compensate for mechanical differences such as tissue thickness (near infrared (NIR) at $931 \mathrm{~nm}$ ). A chlorophyll content index (CCI), proportional to the amount of chlorophyll in the sample, is then calculated (Eq. 1) (Opti-Sciences 2002).

$\mathrm{CCI}=\frac{\text { Absorbance } 931 \mathrm{~nm}}{\text { Absorbance } 653 \mathrm{~nm}}$

Equation 1: chlorophyll content index (CCI), nanometers (nm).

Canopy cover Canopy cover was estimated by taking hemispherical photographs and analyzing them using CAN-EYE (CAN-EYE 2006) software. A Besel Super Wide Fish Eye lens $0.25 \times \mathrm{W}-52025$ with a macro lens was used on a Canon PowerShot A590 IS camera. The camera was set on the ground in between two cotton rows, and the photographs were taken in a vertical upward direction in automatic mode. Illumination conditions were selected in order to clearly differentiate the plants (crop and weeds) from the sky. The CANEYE software was used to derive two indexes from the hemispherical pictures: (i) a plant area index (PAI) (one-sided plant area per unit horizontal ground surface area (CAN-EYE 2006) and (ii) a Fraction of Absorbed Photosynthetically Active Radiation (FAPAR) index. The "No mixed pixel (two classes)" CAN-EYE method was used, consisting in identifying sky pixels, the rest being automatically classified as vegetation. The adjustment of the brightness index only was sufficient to achieve accurate classification. Mean index values per field were computed.

Spatial heterogeneity of in situ parameters The spatial heterogeneity of the fields was computed by using, for height, chlorophyll content, and canopy cover indicators, the standard deviation of every ten measurements by field and then their mean according to management system.

\subsubsection{Satellite imagery and derived indicators}

Satellite programming focused on the acquisition of two images between 1 September and 25 October 2011, but the almost permanent cloud cover in the area did not result in adequate acquisition on these dates. A cloud-free SPOT 5 image on 15 November 2011 was acquired in the 2.5 -m color mode with $2 \mathrm{~A}$ preprocessing level. This image resulted from merging one panchromatic image at a spatial resolution of $2.5 \mathrm{~m}$ with one three-band (green, red, NIR) multispectral image at a spatial resolution of $10 \mathrm{~m}$ (SPOT IMAGE 2010). Another SPOT 5 image, at a spatial resolution of $10 \mathrm{~m}$ and with a short wave infrared (SWIR) band in addition to the green, red, and NIR bands, was acquired on 30 October 2011. This image, however, was slightly cloudy, and only 89 fields could be studied on it. The occasionally small size of the cotton fields in the area and their spatial configuration required using high or very high spatial resolution images. As the acquisition date was very late, the cotton plants were probably mature to senescent and the cotton fiber had probably already been harvested at that time. The cotton fields were digitized in a polygon shapefile in ArcGIS, on the SPOT 5 image, using the field boundary GPS recordings. Using eCognition and R software, two sets of indicators were computed for each field and image spectral band: (i) "spectral indicators", covering mean reflectance, brightness, and all possible ratios of two spectral bands' mean reflectance and (ii) "spatial heterogeneity indicators", covering standard deviation, coefficient of variation, standard error, and a series of gray-level co-occurrence matrix (GLCM) features.

\subsection{Statistical analysis}

The binomial logistic regression technique, a type of the generalized linear model (GLM) technique, was used to find linear models that would best discriminate between the organic and non-organic (conventional and genetically modified) field types.

Three categories of models were investigated: (i) models with in situ indicators only, (ii) models with satellite indicators only, and (iii) models with a combination of in situ and satellite indicators. An exhaustive search to find the best model among all possible models for a given candidate indicator set was carried out using the "glmulti" function of R software. Models with and without pairwise indicator interaction were studied. When the number of possible models was too high because of the size of the candidate indicator set and the use or not of indicator interaction, i.e., when using more than 30 candidate indicators without interaction or more than 10 candidate indicators with pairwise interaction, the candidate indicator set was reduced by progressive indicator selection (elimination of less discriminating indicators) before applying the exhaustive model search. 
The Akaike information criterion (AIC) was used to evaluate the relative ability of each model to separate organic from non-organic cotton fields and to select the best ones. Akaike information criterion presents the advantage to enable simple models to be selected by penalizing models over parameterization and satisfying the parsimony criterion. Models with smaller Akaike information criterion values are better. Models composed of 1 (univariate case) to a maximum of 4 (a reasonable maximum) indicators were computed. Univariate models corresponding to each of the seven in situ indicators were also systematically computed and presented.

The statistical significance of the models was evaluated using the $p$ value of a Mann-Whitney-Wilcoxon (MWW) non-parametric statistical hypothesis test carried out on the model-predicted probabilities of belonging to a management system. The number of fields wrongly classified (predicted probability of belonging to its management system below 0.5 ) was also counted.

Box and whisker plots were used to present, for the three cotton systems, the indicator values for univariate cases and model-predicted probability of belonging to the organic class for multivariate cases.

Leave-one-out cross validation (LOOCV) was used to validate each model. The root-mean-square errors (RMSE) of the predicted probability of belonging to a class of the models calibrated with the 100 fields and of the LOOCV were compared and their differences computed.

All the statistical analysis was carried out using R software.

\section{Results and discussion}

The results table (Table 2) presents, for each indicator category (in situ, satellite, combined) and statistical analysis type (univariate and multivariate, with or without indicator interaction), the best models and related performance and validation parameters. With regard to the multivariate analysis, many other models with a very similar performance exist, but they are not presented here. Based on a selection of the most interesting of these models, Fig. 3 presents graphs showing the discrimination achieved between the three cotton management systems.

\subsection{Univariate model}

\subsubsection{Height}

The mean heights of organic and non-organic cotton (Fig. 3 (1)) show a highly significant difference $(20 \mathrm{~cm})$, with lower heights for organic cotton $(69 \mathrm{~cm}$ for organic and $89.5 \mathrm{~cm}$ for non-organic). The mean height of genetically modified cotton is $9 \mathrm{~cm}$ higher than the mean of conventional cotton. Although the heights' interquartile ranges (IQR) clearly differ between organic and non-organic cotton, the height ranges (minimum and maximum) largely overlap.

The means of the standard deviations of the heights by field (Fig. 3 (2)) for organic and non-organic cotton show a highly significant difference, with higher spatial heterogeneity for organic fields (16.8 for organic and 13.8 for non-organic). Although the IQR clearly differ between organic and nonorganic cotton, the ranges largely overlap.

These results are consistent with the study hypothesis.

\subsubsection{Chlorophyll content}

The mean CCI of organic and non-organic cotton (Fig. 3 (3)) present a significant difference (1.8) with smaller values for organic cotton fields (25.0 for organic and 26.8 for non-organic) which is consistent with the study hypothesis. The CCI interquartile ranges differ slightly between organic and nonorganic cotton, and the $\mathrm{CCI}$ ranges overlap completely.

The means of the standard deviation of the CCI by field (Fig. 3 (4)) for the organic and non-organic cotton show a highly significant difference, with smaller spatial heterogeneity for organic fields (6.0 for organic and 7.0 for non-organic), which is not consistent with the study hypothesis. The interquartile ranges differ slightly between organic and nonorganic cotton, and the ranges largely overlap.

\subsubsection{Canopy cover}

The mean plant area index of organic and non-organic cotton (Fig. $3(5))$ show a highly significant difference $(0.38)$, with lower values for organic cotton $(0.51$ for organic and 0.89 for non-organic), which is consistent with the study hypothesis. Genetically modified cotton has a slightly higher plant area index than conventional cotton. Besides this, the plant area index interquartile ranges do not overlap at all between organic and non-organic cotton. The behavior of the mean FAPAR (Fig. 3 (7)) resembled that of the mean plant area index. The mean plant area index is the most discriminating univariate indicator in this study.

The means of the standard deviations of plant area index by field (Fig. 3 (6)) for organic and non-organic cotton show a highly significant difference, with lower spatial heterogeneity for organic fields ( 0.20 for organic and 0.26 for non-organic), which is not consistent with the study hypothesis. The interquartile ranges differ slightly between organic and nonorganic cotton, and the ranges largely overlap.

\subsubsection{Satellite imagery indicators}

The results obtained from the 30 October image are not presented here because only 89 fields could be studied on it and the discrimination was no better than with the 15 November image. Nevertheless, the SWIR band was generally identified 


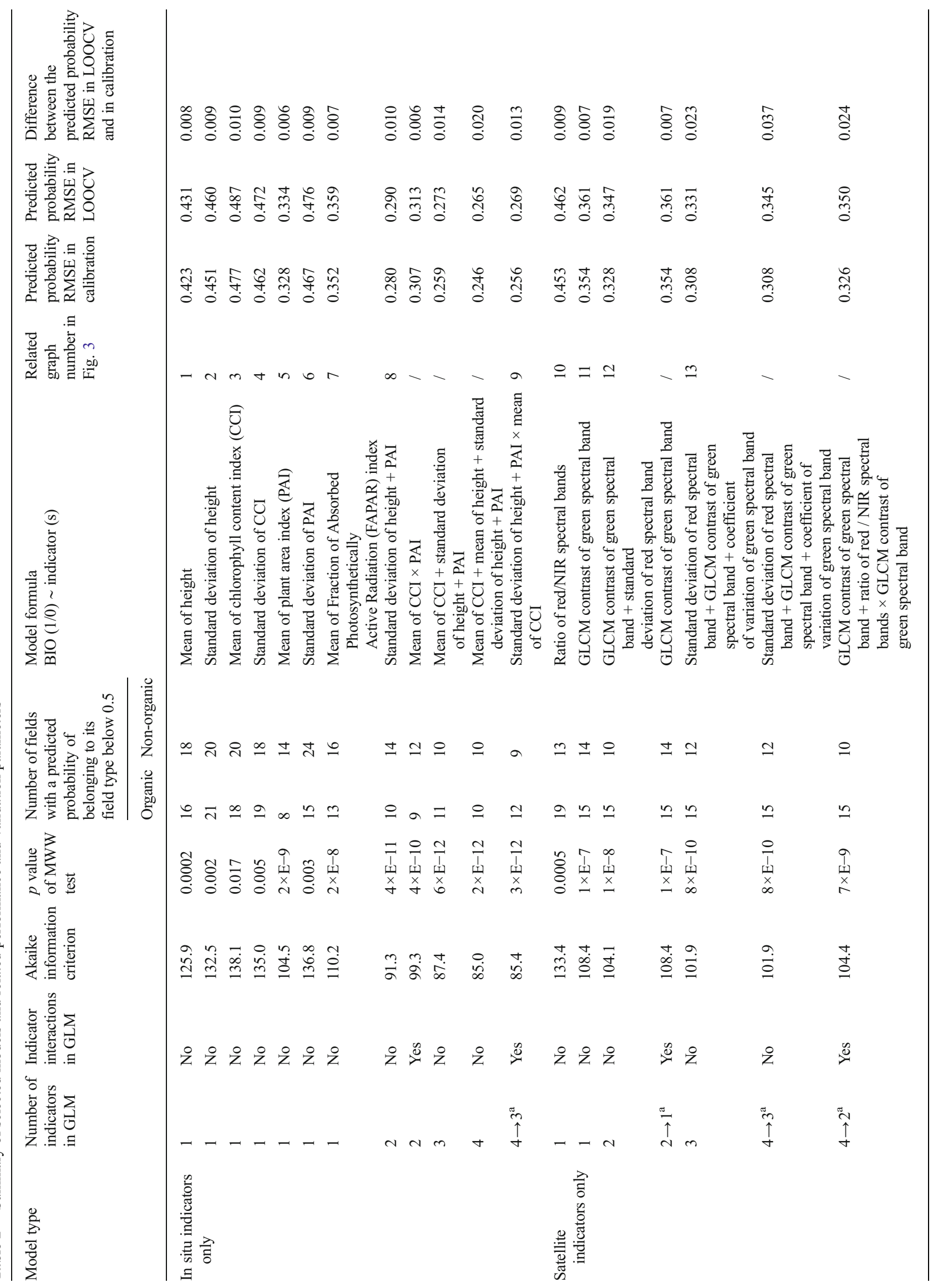




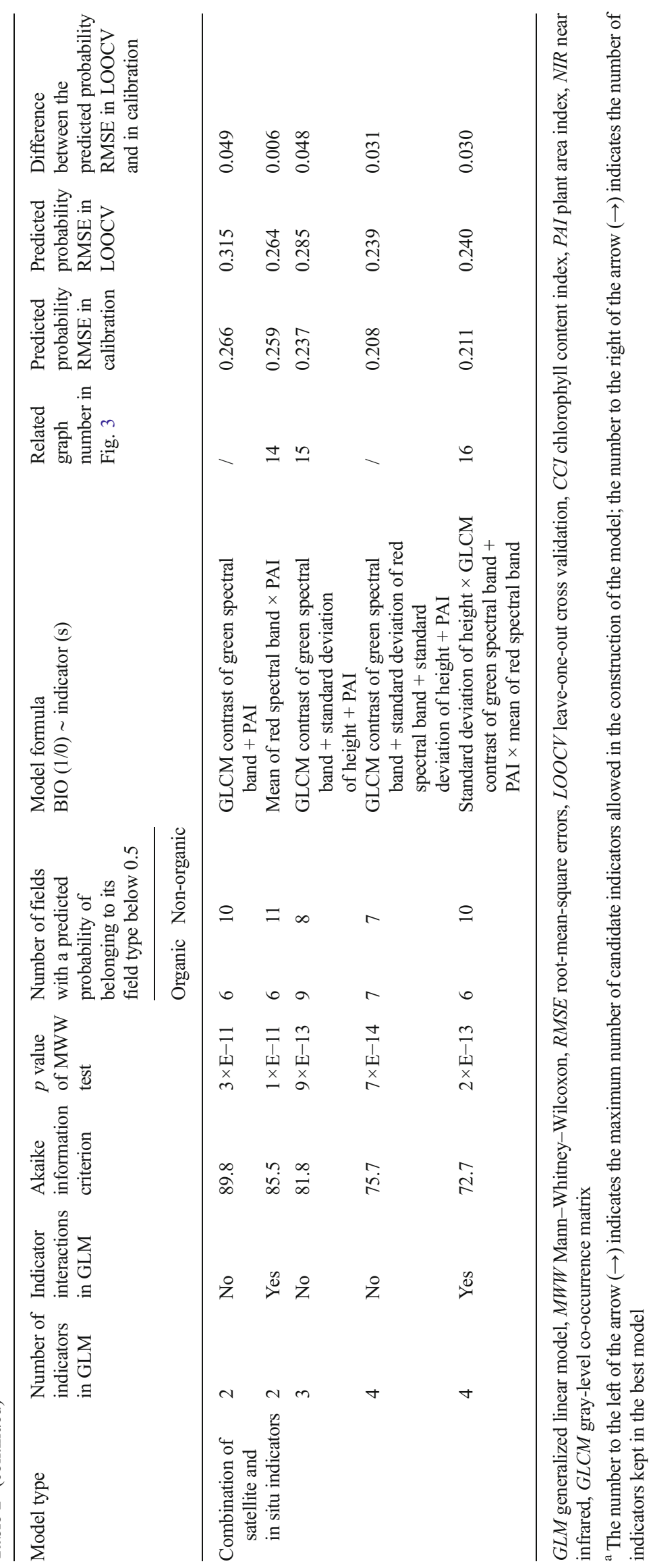


as one of the most discriminating spectral bands and should be considered in further similar studies when available. The results presented here relate only to the 15 November image.

Despite the very late acquisition date, highly significant differences between organic and non-organic cotton fields were observed for both the spectral and spatial heterogeneity SPOT 5 satellite indicators (Fig. $3(10,11))$.

The most discriminating satellite indicators, by far, are the spatial heterogeneity ones. This is probably related to the very late satellite image acquisition at a time when the fields still displayed spatial heterogeneity, but the spectral features had already softened.

The most discriminating spatial heterogeneity indicator is the GLCM contrast of the green spectral band (Fig. 3 (11)) with a $p$ value of $10^{-7}$ and interquartile ranges that nearly do not overlap. Conventional and genetically modified fields show similar values for this indicator while organic fields are more heterogeneous. All spatial heterogeneity indicators computed show higher values for organic fields, which is consistent with the study hypothesis.

The most discriminating spectral indicator is the ratio of the red and NIR (red/NIR) spectral bands (Fig. 3 (10)) with a $p$ value of 0.0005 , interquartile ranges that slightly overlap and ranges that largely overlap between organic and non-organic cotton. Bearing in mind the study hypothesis, however, it could be considered that differences between organic and non-organic cotton fields would be more pronounced earlier in the season when more living vegetation is present.

The very late satellite image acquisition date prevents any direct comparison with the in situ indicator values.

\subsection{Multivariate models}

The multivariate models discriminate better than the univariate ones and are very highly significant, with $p$ values in the range of $10^{-7}$ to $10^{-12}$ and interquartile ranges that do not overlap.

\subsubsection{Multivariate in situ models}

The multivariate in situ models (Fig. $3(8,9))$ generally include both spectral and spatial heterogeneity indicators, reflecting the usefulness and complementarities of these two indicator types. An exception is the two-variate model with indicator interaction, which is composed of two spectral indicators. On this topic, it has been observed that, for all the in situ models generated, the interactions usually consisted of two spatial heterogeneity indicators or two non-spatial heterogeneity ones.

Moving from the best univariate in situ model (Akaike information criterion 104.5) to the best two-variate in situ model (Akaike information criterion 91.3) leads to an important decrease in the Akaike information criterion, which is no more the case with three- or four-variate models (Akaike information criterion 87.4 and 85.0 , respectively).

Multivariate in situ models perform better than satellite ones in this study, probably because of the very late satellite image acquisition date and by the fact that the in situ measurement measures the plants directly.

\subsubsection{Multivariate satellite models}

None of the four-variate models was kept. They were automatically converted into three- or even two-variate models (in the case of interaction). For the two- and three-variate models (Fig. $3(12,13)$ ), the selected indicators are all spatial heterogeneity ones, which can probably be related to the very late satellite image acquisition date as noted earlier. The secondbest two- and three-variate models (not presented), however, have one spectral indicator each.

\subsubsection{Multivariate combined models}

Combined models are always made of both in situ and satellite indicators, reflecting the complementarities of these two indicator types. Here again, for all the combined models generated, the interactions usually consist of two spatial heterogeneity indicators or two non-spatial heterogeneity ones. In addition, the two indicators of each interaction are from two different sources (in situ vs. satellite) (confer the four-variate model with interaction in Table 2).

Combined multivariate models with indicator interaction produce the best discrimination in this study, with, a $p$ value of $10^{-11}$ and an Akaike information criterion of 85.5 for twovariate models (Fig. 3 (14)) and a $p$ value of $10^{-14}$ and an Akaike information criterion of 72.7 for four-variate models (Fig. 3 (16)). Model performance constantly increases with complexity, probably because indicators come from different sources (in situ vs. satellite) and were recorded at different times, bringing in the models complementary rather than redundant information. The number of incorrectly classified fields is also decreased with 21 wrongly classified fields for two-variate in situ models, 26 for two-variate satellite models, and only 16 for two-variate combined models.

\subsection{Model validation}

The prediction RMSE of belonging to a class of the LOOCV are slightly greater than those for corresponding models calibrated with 100 fields and this for all models (Table 2). Their differences are very small compared with the RMSE values themselves, which validate all models. 

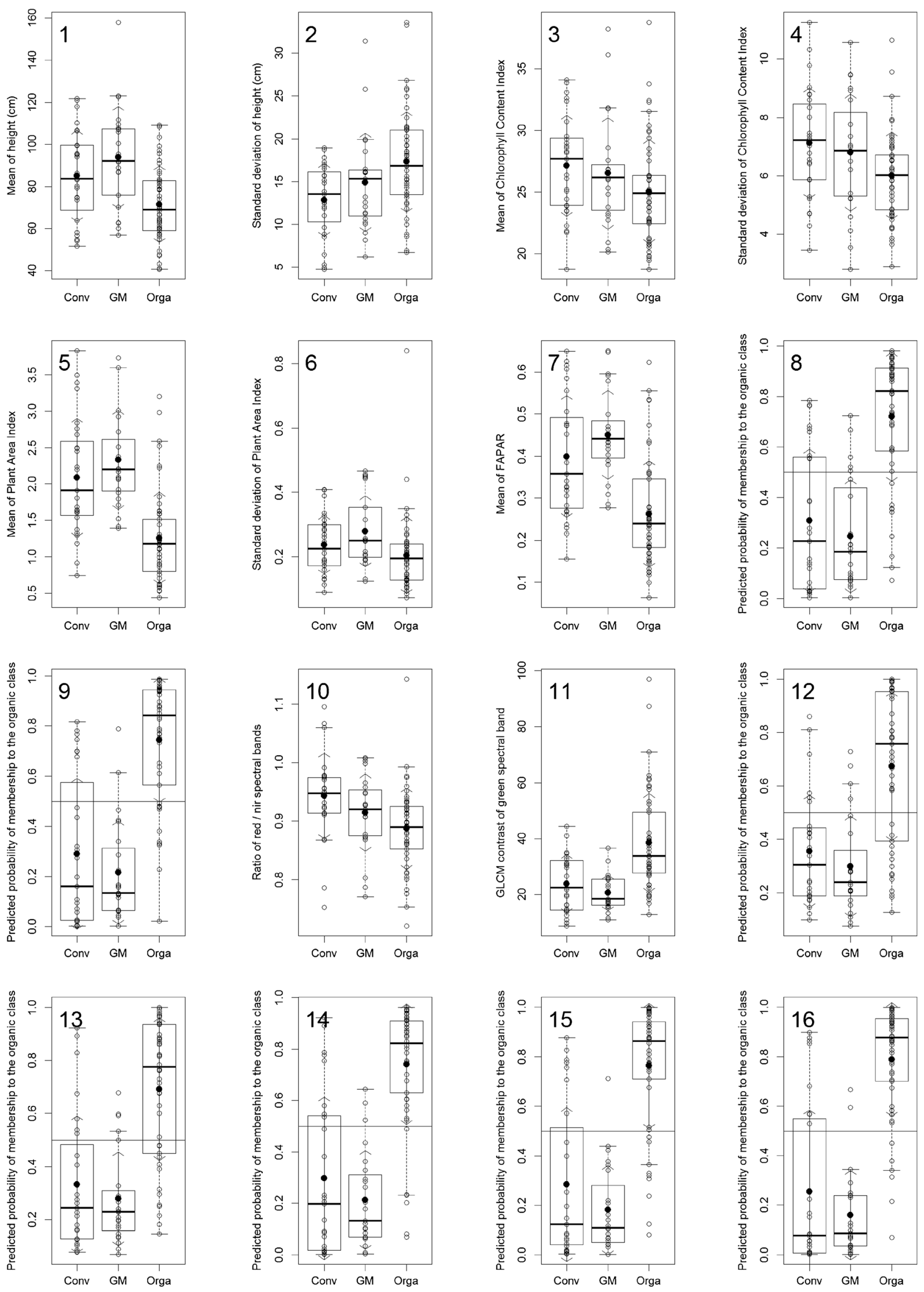
4 Fig. 3 Discrimination obtained among the three cotton management systems with selected indicators and models. Conv conventional, GM genetically modified, Orga organic. Empty circles: indicator values for univariate cases and model predicted probability of belonging to the organic class for multivariate cases; filled black circle: mean value; arrows: standard deviation from mean; box: the interquartile range (IQR) delimited by the first (Q1) and third (Q3) quartiles, with the median indicated by the bold horizontal line; whiskers: the most extreme data point, which is no more than 1.5 times the IQR from the box (i.e., Q1-1.5 $\times \mathrm{IQR}$ and Q3+1.5 $\times \mathrm{IQR}$ ); long horizontal line: the 0.5 probability threshold (multivariate case only)

\subsection{Results summary and discussion}

On the initial hypothesis The results obtained in this study are fairly mixed. On the one hand, most of the univariate indicators (i.e., height and its standard deviation, mean CCI, canopy cover) and those derived from satellite imagery show that organic fields present statistically significant lower general field development and higher spatial heterogeneity, which accords with the initial hypothesis, even though these differences are not always very pronounced, with a large overlap between indicator value ranges over management systems. On the other hand, the standard deviations for plant area index and CCI show lower spatial heterogeneity for organic fields, which is not consistent with the initial hypothesis.

On the technical results All indicators and models enable significant to, most of the time, highly significant difference to be shown between organic and non-organic cotton fields, with satellite indicators, in situ indicators, and combined models showing increasing discriminating ability. Multivariate linear models are more discriminating than univariate ones. Simple models based on satellite imagery show good discrimination performance. More complex three- and four-variate models are consistently more efficient when composed of complementary indicators (spectral vs. spatial heterogeneity, in situ vs. satellite, and multitemporal). Both spectral and spatial heterogeneity indicators prove to be efficient for discrimination, and none of them should be preferred over another. Rather, their combination is worthy. The acquisition of the SPOT 5 image very late in the crop cycle is probably responsible for the comparatively small discriminatory power of its spectral indicators. This, in addition to the fact that no in situ measurement was done at that time, means that the significance and reliability of these indicators should be treated with caution. A timely image, however, would probably have proven to be far more efficient. In this way, the obtained results suggest that there is room for optimism with regard to applying this method, although further validation is needed.

The relevance of the use of remote sensing for this application in the study area can also be discussed Indeed, the difficulties faced in acquiring an adequate satellite image could be seen as indicative of the unfavorable atmospheric conditions in the study area during the rainy and often cloudy growing season, which could be a considerable challenge for implementing an operational remote sensing-based service for discriminating cotton management systems. In addition, the varying presence of trees in cotton fields can strongly influence their reflectance and, in particular, the spatial heterogeneity of the fields as computed from the satellite images. This can range from no trees and a complete agroforestry system combining cotton and a relatively dense Borassus (Palmyra palm) plantation, to the presence of one or two huge mango trees or sparse smaller trees in the field. Besides the direct effect of the trees on reflectance, they have an indirect effect through (i) the favorable impact of their shadow on cotton plants, which extends soil wetness duration, and (ii) the fertilization effect of dead leaves.

Other factors, independent from the cotton management system and having a strong impact on cotton growth and field development, will remain standing in the way of a remote sensing-based discrimination between organic and nonorganic cotton fields. For example, cotton growth stages can vary strongly from one field, farmer, or region to another, depending on the seeding date, itself depending on such factors as the local climatic conditions (Cf. Sect. 2.2). The natural fertility of the soil also considerably influences the plant development.

It should also be noted that the observed differences between organic and non-organic cotton, in the literature and in this study, are due partly to the organic cotton program being relatively new and to the lack of experience among organic cotton farmers and trainers. As suggested by the yields already obtained by elite organic farmers, there is every reason to believe that if organic farming methods are promoted and refined, the current gap between organic and non-organic cotton yields could be considerably reduced in the years to come. This would be particularly likely if organic farmers increased the quantity of organic fertilizers applied, which is, with rainfall, the key factor explaining the cotton yields, and one which seems to be lacking currently.

Finally, it is important to mention that this study was based on a very limited number of fields (100) and samples (1000 most of the time) that are not totally representative of the study area or region. The study results therefore need further validation.

\section{Conclusion}

This study shows that, for the first time, remote sensing techniques can be used for effective discrimination between organic and non-organic cotton crops in the context of West African developing countries. Consequently, provided that further studies with timely satellite image acquisitions validate 
these initial results and that organic cotton performance does not greatly improve, these techniques could help the organic cotton certification process by targeting for priority field control suspect cotton fields declared as organic. Further research should focus on determining the ideal phenological stage for cotton management system discrimination by remote sensing in West Africa and on evaluating the use of a broader spectral range (SWIR and over).

Acknowledgments Helvetas Swiss Intercooperation Burkina Faso, for their important documentation on organic cotton production in Burkina Faso and their advice on the field survey preparation.

The National Union of Cotton Producers of Burkina Faso (Union Nationale des Producteurs de Coton du Burkina Faso (UNPCB)), which enabled the field survey of organic cotton fields to be conducted and participated in it.

The Société Burkinabé des Fibres Textiles (SOFITEX) which allowed the field survey to be conducted on conventional and genetically modified cotton fields.

The Centre National d'Etudes Spatiales (CNES), which, through its ISIS program, provided the SPOT 5 images at low cost (SPOT data Copyright CNES (2011), Distribution Spot Image S.A., ISIS Program Http://www.isis-cnes.fr/IntroPage.do).

\section{References}

CAN-EYE (2006) CAN-EYE software documentation, Output Variables. Definitions and theoretical background

CDE, Centre for Development and Environment of the University of Berne, Helvetas Burkina Faso (2008) Impact study on organic and Fairtrade cotton in Burkina Faso. Fact sheet

CDE, Centre for Development and Environment of the University of Berne, Pineau M, Gabathuler E, Giger M (2009) Etude d'impact du programme coton bio et équitable d'Helvetas au Burkina FasoCampagne 2008/09

CIRAD, Centre de Coopération Internationale en Recherche Agronomique pour le Développement (2006) Le coton-Fil des temps, des marchés \& des cultures

Denis A, Desclee B, Migdall S, Hanssen H, Bach H, Ott P, Tychon B Can satellites help organic crop certification? In: Billen R, Binard M, Hallot P, Donnay J-P (eds) SAGEO 2012, Liège, Belgium, 6-9 November 2012 (2012). pp 178-181. http://hdl.handle.net/2268/ 133126

European Commission (2007) Council Regulation (EC) No 834/ 2007 of 28 June 2007 on organic production and labelling of organic products and repealing Regulation (EEC) No 2092/91.(1-23)

FAO, German Weather Service (DWD), Grieser J (2006) New LocClim 1.10 -local climate estimator

GRAIN (2004) Bt cotton at Mali's doorstep: time to act!

Helvetas Burkina Faso (2004) Programme de promotion du coton biologique-brochure de 2 pages en ligne

Helvetas, Abdoulaye O, Lazare Y, Siaka D, Frank E, Raphael D (2008) Guide de production du coton biologique et équitable. Un manuel de référence pour l'Afrique de l'Ouest. In: Helvetas Association Suisse pour la Coopération Internationale (ed)

Le Houérou HN, Popov GF, Corra M, Food and Agriculture Organization of the United Nations (1981) An eco-climatic classification of intertropical Africa

Noisette C (2006) Burkina Faso-Des variétés burkinabées de coton transgénique expérimentées. Inf'OGM: un journal bimestriel pour suivre l'actualité internationale sur les OGM $\mathrm{N}^{\circ} 79$ (Octobre 2006)

Opti-Sciences I (ed) (2002) CCM-200 Chlorophyll content meter, instruction booklet

Some S, Ministère du Commerce, de la Promotion de l'Entreprise et de l'Artisanat, Burkina Faso (2008) The future of organic agriculture in Africa: the case of Burkina Faso

SPOT IMAGE (2010) SPOT IMAGE, Technical sheet, Resolutions and spectral modes 